\title{
Donald A.B. Lindberg, pioneer in biomedical and health informatics: His involvement in creating professional organizations
}

\author{
Jan H. van Bemmel ${ }^{\mathrm{a}, *}$, Marion J. Ball ${ }^{\mathrm{b}}$ and Edward H. Shortliffe ${ }^{\mathrm{c}}$ \\ ${ }^{a}$ Medical Informatics, Erasmus University Rotterdam, Rotterdam, The Netherlands \\ ${ }^{\mathrm{b}}$ Multi-Interprofessional Center for Health Informatics, University of Texas, Arlington, Texas, USA \\ ${ }^{\mathrm{c}}$ Department of Biomedical Informatics, Columbia University, New York, USA
}

\begin{abstract}
Among the many contributions of Donald A.B. Lindberg was his work on behalf of a variety or professional organizations in the field of biomedical and health informatics. These began during his early days at the University of Missouri and continued throughout his 30 years at the National Library of Medicine. This chapter summarizes that work, which occurred both through his personal efforts and through the impact of the NLM under his leadership. Examples include his role in the development of organizations themselves (e.g., the International Medical Informatics Association, the American College of Medical Informatics, and the American Medical Informatics Association) and also his contributions to the professional scientific meetings that have advanced the field (e.g., the Symposium on Computer Applications in Medical Care, MEDINFO, and the AMIA Annual Symposium).
\end{abstract}

Keywords: Donald A.B. Lindberg, medical informatics, International Medical Informatics Association, American Medical Informatics Association, U.S. National Library of Medicine

\section{Introduction}

Donald A.B. Lindberg M.D. was a pioneer in many fields, including biomedical and health informatics. Known especially for his role as Director of the National Library of Medicine (NLM), he was a great advocate and promoter of the informatics field. Throughout his career, he maintained key interests in both main themes and in details. Nevertheless, amid all his organizational activities, Lindberg remained a scientist: curious, open to new ideas, positively responsive to the unexpected, innovative, and creative.

In this chapter we focus on Dr. Lindberg's important contributions to the organizational development of biomedical and health informatics, which we simply call informatics hereafter for brevity. Note that he was based at the University of Missouri until, in 1984, when he became NLM director and moved from Columbia, Missouri to Bethesda, Maryland (where the NLM is located on the campus of the National Institutes of Health $[\mathrm{NIH}])$. Dr. Lindberg served at NLM for a remarkable 31 years until his retirement in

\footnotetext{
*Corresponding author: Jan H. van Bemmel, Ph.D., Emeritus Professor of Medical Informatics, Erasmus University, Rotterdam, The Netherlands. E-mail: janhvb@gmail.com.
} 
2015. Throughout his career, both at Missouri and subsequently at NLM, he was actively involved with a wide variety of professional organizations and meetings related to the informatics field.

Although this chapter is not about his personal research work, we note that Lindberg always surrounded himself with a team of top researchers and superb staff members. That many had prolonged careers at NLM under Don's leadership demonstrates that he was highly professional, shaped a positive workplace environment, and exhibited heartfelt concerns for his coworkers. A few key references to Lindberg's varied work appear at the end of this chapter [1-5]; more appear in [6].

In this chapter we start by discussing how Lindberg's training and medical background brought him naturally to the field of informatics. We then note how his growing reputation as a scientist and leader in the field enabled him to play key roles in the development and evolution of several key organizations and meetings, many of which continue to define the field until today. These include both professional societies in the U.S. and the growth of an international community of professionals in the field. We then turn to how his leadership at the NLM itself has influenced the organization and growth of the field. Finally, since all chapter authors had close personal relationships with Don over many decades, we close with some personal observations about the man, his leadership, and his impact on people both professionally and personally.

\section{Biomedical background - ideal for contributions to the field of informatics}

Lindberg received his Bachelor of Arts degree magna cum laude from Amherst College and his MD degree from the College of Physicians and Surgeons at Columbia University. While at Amherst, he studied experimental embryology and contributed to the literature on limb growth and regeneration. He received his postdoctoral training in anatomic and clinical pathology at Columbia-Presbyterian Medical Center in New York and began his career as a pathologist.

In 1963, he founded one of the first medical computer centers in the U.S. at the University of MissouriColumbia, where he served on the medical faculty. Of course, Don first applied computers to his own field of pathology. He also was one of the early contributors to computer-assisted medical decision-making and education. He went on to garner many appointments and honorary doctorates at prestigious universities. Don published extensively in the fields of pathology as well as informatics, authoring several books, book chapters, and more than 200 articles and reports. He served as an editor and editorial board member of nine journals, including Methods of Information in Medicine and the Journal of the American Medical Informatics Association. For additional details, please refer to [7].

When Jan van Bemmel visited him at his home in Columbia Missouri in February 1983, Don proudly showed his recently purchased IBM personal computer, equipped with an Intel 8080 - now a collector's item. At that time, he was, in addition to being Professor of Pathology, also Professor of Information Science at the University of Missouri-Columbia.

\section{Pioneering role in medical and health informatics}

In discussing Lindberg's pioneering role in informatics organizations, we first discuss his key contributions to the evolution of organized informatics in the U.S. This work extended over many years, beginning in Missouri but growing in importance after his move to the NLM. As we describe, his work to support the creation of organizations in the U.S., and the scientific meetings for which they are known, was key - and is reflected in the professional organizations that we see today. We then focus on his role in global 
organizations, where he became a key international figure as the field grew. These international activities include development of the principal international society for the informatics field, efforts to enhance the role of informatics in assuring quality and reliability of health information, and the evolution of a major peer-reviewed journal in the field.

\subsection{AAMSI, SCAMC, ACMI and AMIA}

To address Lindberg's impact in the U.S., we must begin by introducing briefly the early days of the development of American professional activities related to informatics. In 1977, Helmuth F. Orthner, $\mathrm{Ph} . \mathrm{D}$., and William Yamamoto, Ph.D., both at George Washington University (GW) in Washington, began hosting a local, U.S. District of Columbia area conference that they titled the Symposium on Computer Applications in Medical Care (SCAMC) ${ }^{1}$. Lindberg was a presenter at the initial meeting and a regular attendee in subsequent years. As interest in the meeting grew, Thomas Piemme, M.D., GW Medical School's Assistant Dean and Director of Continuing Medical Education, helped to secure funding for an expanded version of the meeting, and marketed it broadly both nationally and internationally. Following the success of the expanded meeting, Piemme legally incorporated SCAMC, and became the organization's Executive Director.

Piemme had first met Lindberg in 1966, at which time both had been appointed as Markle Scholars ${ }^{2}$. By 1982, when Don was at the University of Missouri and was chairing the NLM's grant review group (then known as the Biomedical Library Review Committee), he was already highly visible in the biomedical computing community. Accordingly, Piemme and the SCAMC Board of Directors recruited Lindberg as their first board member from outside the Washington, DC area. Only two years later, Don moved to the Washington area to assume his leadership role at NLM and continued to be highly involved with SCAMC oversight.

Shortly after Don's appointment to the SCAMC board, Piemme was elected to the Board of Directors of the American Association for Medical Systems and Informatics (AAMSI), where Don also was to serve on the Board in the mid-1980s. AAMSI was the major U.S. membership organization in the field and it held its own annual meeting every spring, typically on the West Coast to avoid direct conflicts with SCAMC.

Meanwhile, at the 1982 SCAMC meeting in Baltimore, Morris F. Collen, M.D. invited Lindberg, Piemme, Edward H. Shortliffe, M.D., Ph.D., and M. Scott Blois, M.D., Ph.D., to a private meeting in which he suggested creation of an American College of Medical Informatics (ACMI), to consist of nominated and elected Fellows. In 1985, the first 52 ACMI members were elected by 100 individuals who had been nominated to be founding fellows. ACMI was in turn incorporated and Scott Blois served as the first ACMI President, with Tom Piemme as Secretary/Treasurer. Piemme's GW office initially managed the operation of ACMI, as it did SCAMC.

By 1988, leaders of the major American informatics organizations (all of which involved Lindberg in their leadership) - AAMSI, SCAMC, and ACMI - deemed it illogical to maintain three separate corporations since their functions were complementary. The organizations had overlapping Boards of Directors, similar activities, and common members/attendees. Led by ACMI President Homer R. Warner M.D., Ph.D., and AAMSI President William W. Stead, M.D., their two organizations were fully supportive of discussions regarding merger. By contrast, SCAMC President Yamamoto, and some of the other original

\footnotetext{
${ }^{1}$ Information in this section derives in part from an interview recorded with Thomas Piemme, MD just days before his death in April, 2021.

${ }^{2}$ See https://www.nature.com/articles/163437c0 and https://www.markle.org/
} 
SCAMC Board members from Washington, initially opposed a merger despite the urging of many of the other board members, including Lindberg. This delayed progress temporarily. When Shortliffe succeeded Yamamoto as SCAMC President, plans to merge regained momentum.

The three boards agreed that it would be in the best interests of the new entity - to be called the American Medical Informatics Association (AMIA) - if they could identify a particularly respected individual to be the founding President of the organization. The three legacy organization presidents (Warner, Stead, and Shortliffe) were excluded from consideration by mutual agreement. Lindberg was the obvious choice. He was approached in late 1988 about becoming the founding President (board chair) of AMIA and agreed to serve. Of note, Don was appointed by the outgoing boards since the entity did not yet have a voting membership. He started to chair meetings of the interim board. This process is documented in an October 17, 1988 letter written by AAMSI President Stead to Lindberg. That letter identified Don as both President of AMIA and Director of the National Library of Medicine. In the letter, the AAMSI Board of Directors set forth conditions for AAMSI's merger into AMIA.

In 1988-89, Piemme arranged for AMIA to become incorporated as an organization headquartered in Washington, DC. While that initially created a shell corporation, the logistics of dissolving three corporations, and creating a new, non-profit, tax-exempt 501-(C)(3) organization required U.S. federal government approval. Funds from ACMI, SCAMC, and AAMSI could not be transferred to AMIA until the Internal Revenue Service approved AMIA's educational/charitable status.

There was broad agreement that the new organization should establish its own staff and space, which explains why AMIA opened offices in Bethesda, to be close to Don's workplace at NLM. It continues to be based in Bethesda today. AAMSI members all automatically became AMIA members. The College (ACMI) worked out a scheme whereby it would be part of AMIA but would be self-governed using rules adapted from its initial bylaws from 1984. Per the merger agreement forming AMIA, for its first five years AMIA continued to call its annual conferences SCAMC. Thereafter the meeting was called the AMIA Annual Symposium, which continues to this day. After AMIA was officially formed through the formal merger of AAMSI, SCAMC, and ACMI, and with Lindberg's leadership, it quickly grew as the principal society for informatics in the U.S.

The AMIA Board meeting of January 9, 1990 was led by President Lindberg. Other AMIA Board (BOD) members at that time, in addition to Lindberg, Warner, and Shortliffe, included Michael Ackerman, Ph.D.; G. Octo Barnett, M.D.; Morris F. Collen, M.D.; W. Edward Hammond, Ph.D. (Treasurer); Daniel K. Harris; Edward J. Hinman, M.D.; Frank M. Holden, M.D.; Pat Jacobs, R.N., M.N. (Secretary); Clement J. McDonald, M.D.; Helmuth Orthner, M.D.; and Judith Ozbolt, R.N. In attendance as guests were Joyce Mitchell, Ph.D. and Randolph A. Miller, M.D. - the respective Program Chairs of the forthcoming AMIA Spring and Fall AMIA/SCAMC meetings. These were the first national meetings held under the AMIA banner. At the January board meeting, the AMIA legal counsel noted that the official incorporation of AMIA as a legal entity would not be completed until later in 1990, due to the requirements of registering as a 501 (C) (3) tax exempt organization. Nevertheless, the Board had the authority to act as if incorporation was in place.

At subsequent 1990-1991 AMIA Board Meetings, under Lindberg's guidance, the following noteworthy events occurred: approval of annual ACMI retreats; creation of AMIA's Professional Specialty Groups (later called AMIA Working Groups); creation of the AMIA Executive Director position; creation and population of AMIA Standing and Ad Hoc Committees; and establishment of procedures for election of new AMIA Board members. The AMIA Board in August 1990 directed the Publications Committee Chair to pursue possible creation of AMIA's own new journal (which eventually became JAMIA). Based on a November 1991 report of the AMIA Publications Task Force, the AMIA Board of Directors voted 
that AMIA would own Copyright to all editorial material published in its future journal; that AMIA would appoint the journal Editor after discussion with the publisher; that AMIA would have control of the scientific content of the journal; and that journal content would include material appropriate to the organization and to the field of informatics. AMIA membership at the end of 1990 was 1,124; at the end of 1991 it was 1,911. Lindberg completed two subsequent 2-year terms on the AMIA Board (one was as Past President) after his initial 1989-91 term as founding AMIA President ended. As the above details reveal, Don's leadership, dedication, and inspirational example were key elements in the early initiation and success of AMIA.

Jan van Bemmel, although not an American, can testify to Don's diligent diplomacy, having been present at the meeting where the decision was made to incorporate SCAMC, ACMI, and AAMSI into a new organization, thereby creating AMIA. This meeting took place in 1988 on top of the San Francisco Hilton, the same place where MEDINFO 2004 would be hosted by AMIA 16 years later. Marion Ball joined the Board of AMIA and later formed the bridge from AMIA to the International Medical Informatics Association, IMIA.

\subsection{IMIA and MEDINFO}

Started by Parisian informatician François Grémy, MD, the International Medical Informatics Association (IMIA) came into existence in 1967, within the International Federation for Information Processing (IFIP), as Technical Committee 4 (TC4), a special interest group. In the early 1980s, Lindberg was appointed to serve as the U.S. representative to IMIA by the American Federation of Information Processing Societies (AFIPS). Don remained involved with IMIA and participated as an active proponent. While still at the University of Missouri, Don accepted an invitation to chair the organizing committee for the upcoming 1986 MEDINFO - IMIA's triennial international meeting. Van Bemmel chaired the program committee, with Shortliffe as vice-chair. Lindberg asked Piemme and SCAMC to host the meeting in Washington, DC. The meeting was highly successful nationally and internationally.

Lindberg used his experiences with AAMSI and IMIA (in part) as a model for how he organized AMIA. Subsequently, the U.S. again hosted MEDINFO in 2004 in San Francisco, this time through AMIA. Dr. Lindberg was instrumental again - as in the past. In the background, he helped to arrange for NLM's Fogarty International Center to provide support for as many people as possible from Third World countries to participate in MEDINFO. He also had done so for preceding MEDINFOs. The title of that 2004 MEDINFO, Building High-performance Healthcare Organizations, fit very well with Don's vision for high performance computing in biomedicine.

\subsection{HON, Health-on-the-Net}

The Health-on-the-Net Foundation (HON) was created in 1995 in Geneva by Jean-Raoul Scherrer, MD, $\mathrm{PhD}$. HON became one of most respected not-for-profit portals to medical information on the Internet. It not only widely opened medical and health information to the general public, but also incorporated a Code of Conduct, the HON Code. Sites could apply to be audited, reviewed, and endorsed by HON. The presence of the HON Code logo on a health-related Web Site ensured that medical information offered on it conformed to the principles of trustworthiness and reliability embodied in the HON Code. Lindberg served as the President of the HON Council during its early years, after Scherrer.

van Bemmel and Ball also participated in the Council of Health on the Net. Most Council meetings took place annually in Geneva and surroundings, first operating under the leadership of Scherrer, and later under the guidance of Dr. Celia Boyer. HON was extraordinarily successful and won the European Award for e-Health. 


\subsection{Methods of information in medicine}

Over many years, Lindberg and van Bemmel served as joint Editors-in-Chief of the oldest journal in the informatics field - Methods of Information in Medicine, or in shortened form, 'Methods'. In 1988 they took over the helm from Dr. Gustav Wagner from Heidelberg, founder and first Editor-in Chief, who had originally started the journal three decades earlier in the German language before transitioning after several years to English. Lindberg and his colleagues have been supportive in stimulating the worldwide visibility of this journal and have authored many leading contributions in its pages.

\section{NLM and informatics}

Under Dr. Lindberg's leadership, the NLM became the world's largest fully digital biomedical library. The Library has a statutory mandate from the U.S. Congress to apply its resources broadly to the advancement of medical and health-related sciences. It collects and organizes biomedical information, and makes it available to investigators, educators, and practitioners, while carrying out programs designed to strengthen existing medical library services and develop new information dissemination methods in the United States. Dr. Lindberg's and NLM's roles in those activities are detailed elsewhere in this book, including the outreach efforts for NLM bibliographical content embodied in the Grateful Med and PubMed interfaces. During the years 1992-95, Don was also the Director of the National Coordinating Office for High Performance Computing and Communications [8]. In addition, he served from 1996 to 2000 as the US Coordinator for the G-7 Global Health Applications Project, nominated by the Secretary of the United States Department of Health and Human Services (DHHS).

A valuable feature of NLM is its internal research and development activities. The latter are carried out in NLM's Lister Hill National Center for Biomedical Communications (LHC) and the National Center for Biotechnology Information (NCBI) [9]. The NCBI is the result of long-range planning that Don undertook in the 1980s. His contributions to many such NLM initiatives are detailed in [6]. They all have had a profound impact on the informatics discipline as well as on the informatics meetings and organizations that we have earlier discussed.

\section{Some private and personal observations}

Don played a pivotal role in the early development of working groups within the International Medical Informatics Association (IMIA). He helped establish the very first Hospital Information Systems working group that was formed in Cape Town, South Africa in 1979. Not only did Don contribute great value to many international initiatives, spanning many countries around the world; he also had the gift of being an unusually caring husband and father. Don, on most of his national and international trips, took one of his three sons with him to broaden that boy's world view and to allow him to experience varied cultures, both in the United States and abroad - part of what he considered important for each son's education.

We can say that the tremendous professional contributions that Don has made on an intellectual and academic arena can also be equated with the humanity and humility that he demonstrated throughout his entire life. Don was truly a man for all seasons, with a scientific way of thinking and contributions that will live on for decades to come, reflecting not only how he served as a physician and a professor, but also as one of the longest tenures of leadership for an NIH institute.

Another special and less known fact about Don's accomplishments is he was a talented photographer, taking superb pictures all over the world. He published several volumes of his exquisite photographs. 
Many of them hang in various areas of the National Library of Medicine. The Memoirs section of this book provides additional details regarding the above comments.

We cannot end without saying that Don never underestimated the importance of his wife Mary, to whom he was utterly devoted. She was, indeed, the wind under his wings. Mary is a nurse who provides home care as a Hospice Volunteer.

\section{References}

[1] D.A.B. Lindberg and E.R. Siegel, On assessing the impact of medical information: Does MEDLINE make a difference? Methods Inf Med 30: (1991), 239-240.

[2] D.A.B. Lindberg, B.L. Humphreys and A.T. McCray, The Unified Medical Language System, Methods Inf Med 32: (1993), 281-291.

[3] B.L. Humphreys, D.A.B. Lindberg, H.M. Schoolman and G.O. Barnett, The Unified Medical Language System: An informatics research collaboration, J Am Med Inform Assoc 5: (1998), 1-11.

[4] D.A.B. Lindberg, Medicine in the 21st century: Global problems, global solutions, Methods Inf Med 41: (2002), $235-236$.

[5] M.F. Collen and M.J. Ball (eds), The History of Medical Informatics in the United States, Springer-Verlag, London, 2015.

[6] B.L. Humphreys, R.A. Logan, R.A. Miller and E.R. Siegel (eds), Transforming Biomedical Informatics and Health Information Access: Don Lindberg and the U.S. National Library of Medicine, IOS Press, Amsterdam, 2021.

[7] L.C. Kingsland 3rd and C.A. Kulikowski, A scientific mind embraces medicine: Donald Lindberg's education and early career. in: Transforming Biomedical Informatics and Health Information Access: Don Lindberg and the U.S. National Library of Medicine, B.L. Humphreys, R.A. Logan, R.A. Miller and E.R. Siegel (eds), IOS Press, Amsterdam, 2021.

[8] M.J. Ackerman, S.E. Howe and D.R. Masys, Don Lindberg, high performance computing and communications, and telemedicine. in: Transforming Biomedical Informatics and Health Information Access: Don Lindberg and the U.S. National Library of Medicine, B.L. Humphreys, R.A. Logan, R.A. Miller and E.R. Siegel (eds), IOS Press, Amsterdam, 2021.

[9] D.R. Masys and D.A. Benson, Don Lindberg and the creation of the National Center for Biotechnology Information. in: Transforming Biomedical Informatics and Health Information Access: Don Lindberg and the U.S. National Library of Medicine, B.L. Humphreys, R.A. Logan, R.A. Miller and E.R. Siegel (eds), IOS Press, Amsterdam, 2021. 